\title{
Condiciones laborales de Trabajadores Sociales en el Poder Judicial de Neuquén
}

\section{Work conditions of the social workers from the Judiciary of Neuquén}

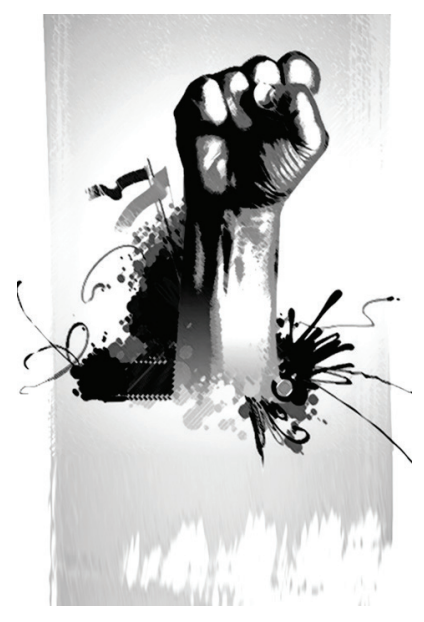

Martha Valdevenito*

Resumen: El presente artículo se propone recuperar la experiencia organizacional, sindical y política, de las Trabajadoras Sociales del Poder Judicial de Neuquén. Este proceso de sindicalización del sector se extiende hasta el año 2007. El análisis pone énfasis en las tensiones que se producen entre la "cuestión social" y las formas de enfrentamiento que asume una institución del Estado como el Poder Judicial, constituyendo a la profesión como un permanente campo de lucha.

Palabras Claves: Trabajo Social. Cuestión Social. Condiciones Laborales. Sindicalización. Poder Judicial.

\begin{abstract}
This article aims at recovering the organizational, political and union experience of the social workers from the Judiciary of Neuquén. Such a unionization process of the sector went on until 2007. The analysis emphasizes the tensions between the "social issue" and the ways the Judiciary confronted it, which made the profession become a permanent field of struggles.

Keywords: Social work. Social issue. Work conditions. Unionization. Judiciary

* Licenciada en Servicio Social (UN Comahue), Especialista en Políticas Sociales y Derechos de la Infancia, (Universidad Nacional Del Comahue, Unicef), Especialización en Estudios de las Mujeres y Género; maestranda en Trabajo Social (Universidad Nacional de La Plata), Trabajadora Social del Gabinete Interdisciplinario del Poder Judicial de Neuquén Capital, Argentina. E-mail: mvaldevenito@yahoo.com.ar.
\end{abstract}




\section{Introducción}

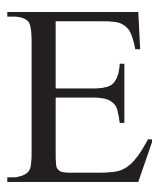

1 presente artículo tiene la intención de recuperar la experiencia organizacional, sindical y política de las Trabajadoras Sociales del Poder Judicial de la provincia de Neuquén que va a culminar con la Sindicalización del Sector en el año 2007. La propuesta es hacer un recorrido histórico desde la inserción de la profesión en este espacio socio ocupacional en el año 1970 hasta el año 2010. La mirada se va a centrar en las formas de organización del colectivo profesional en el contexto de las tensiones existentes entre la demanda que provoca la "cuestión social" y el enfrentamiento que realiza una de las instituciones del Estado para dar respuesta.

Recuperar este proceso ha sido posible a partir de la relación con la academia en instancias de formación posibilitando romper con la enajenación que caracteriza el proceso de trabajo, superando transitoriamente las expresiones del cotidiano: fragmentación, pragmatismo, espontaneísmo, para incursionar en procesos de reflexión que posibilitaron apropiarnos de esa realidad caótica y descifrar sus conexiones macroscópicas.

La sindicalización fue protagonizada por Trabajadoras Sociales y Psicólogos, ambas profesiones han desarrollado históricamente alianzas y conformado un colectivo para enfrentar las condiciones laborales de la institución. Este artículo recupera las implicancias y transformaciones que ese proceso significó para la intervención en el Trabajo Social y el desarrollo de otras experiencias ligadas a la formación, a la relación con la Universidad y al Colegio de Profesional, posibilitando un intercambio que coloca a la profesión en relación con debates actuales de la región.

Compartimos la concepción que nos aporta Marilda Iamamoto (1998) cuando nos propone que la práctica profesional se inserta en el juego de relaciones sociales y de sus mecanismos de poder económico, político y cultural preservando las particularidades de la profesión en tanto actividad inscripta en la división social y técnica del trabajo.

El Trabajo Social en el ámbito judicial representa un espacio ocupacional particular vinculado a la intervención de la "cuestión social" que se expresa en la justicia como una institución más del Estado. La intervención profesional excede la denominada "función pericial" y se vincula a las constantes transformaciones societarias expresadas en los marcos legales. Representa un campo de tensiones 
donde el Trabajador Social vende su fuerza de trabajo (Iamamoto, 1992, p. 202), recibe una demanda de la Institución judicial y va construyendo constantemente estrategias para lograr el acceso al servicio de Justicia por parte de los usuarios.

La carta orgánica del Poder Judicial de Neuquén establece en el art. $11^{1}$ que "los profesionales auxiliares de la justicia son funcionarios del poder judicial". Este ordenamiento legal visualiza claramente al Estado como regulador y controlador de la fuerza de trabajo. Tal definición ha constituido el fundamento histórico (1970 a 2007) para negar de manera sistemática derechos laborales, sindicales y políticos al sector.

La crítica al cotidiano (Netto, 2012) posibilitó trascender la mirada del expediente provocando reflexiones más allá de cada instrumento legal que conforma la intervención del Trabajador Social, para centrar el análisis en los fundamentos de la profesión en la institución justicia y la reconstrucción de la particularidad de la intervención en ese ámbito.

Este proceso se colectivizó a partir de la puesta en marcha de las primeras jornadas de capacitación: "El Trabajo Social en la Justicia desde una perspectiva Histórico Crítica" "El debate contemporáneo del Trabajo Social en el ámbito de la Justicia", dirigidas a Trabajadoras Sociales de Neuquén y Río Negro y del Ministerio de Desarrollo Social (MDS), organismo ejecutor de las leyes de violencia de género y protección de la infancia. La experiencia ha resultado una de las conquistas derivadas del proceso de sindicalización, en tanto, se modificaron las condiciones laborales apremiantes del período posterior a la crisis del 2001, posibilitando un nuevo contexto que plantea otras preocupaciones a resolver en el marco de las instancias reflexivas y propositivas de los espacios del Trabajo Social.

\section{Organización y condiciones formales de Trabajo en el Poder Judicial}

Las Trabajadoras Sociales de la Justicia de la Provincia de Neuquén constituimos veinticinco profesionales distribuidas en las cinco circunscripciones que abarcan el territorio. Se trata de Neuquén Capital que concentra la mayor parte de las trabajadoras sociales, nucleadas en el Gabinete Interdisciplinario del fuero de

1. Decreto Ley n. 1.436, Carta orgánica del Poder Judicial de Neuquén. 
Familia que depende de Superintendencia del Tribunal Superior de Justicia (TSJ) y otro grupo de compañeras/os ubicados en las Defensorías de Niñez y Adolescencia dependiente de las Defensorías del Tribunal de Justicia.

Las otras cuatro circunscripciones tienen como cabeceras a Cutral Có, Zapala, Junín de los Andes, Villa La Angostura y Chos Malal. Allí cada Juzgado Civil y Defensorías de Niñez cuenta con Trabajadoras Sociales y Psicólogos.

Los ingresos a Justicia son a partir de concursos de antecedentes y oposición, inclusión formal inmediata a partir de una categoría de ingresante, obra social, vacaciones y aguinaldo garantizados por el acceso a la planta judicial.

Actualmente los tribunales evaluadores se encuentran conformados por Trabajadoras Sociales y un abogado, veedores sindicales y del colegio de profesionales. La conformación de los tribunales ha resultado un ámbito de tensión y disputa, dado que, anterior al proceso de sindicalización, los evaluadores se encontraban conformados por jueces magistrados, psiquiatras, médicos y/o psicólogos como agentes legitimados por la institución para evaluar un cargo de Trabajador/a Social omitiendo la figura de un Trabajador/a Social en este ámbito.

La planta del Poder Judicial para los Trabajador/as Sociales representa un ámbito de ingreso formal al mercado de trabajo con todas las consecuencias de allí derivadas. Las condiciones laborales de los contratos precarizados que tuvieron vigencia en la década de 1990 conformaron parte del pliego de demandas del sector, siendo erradicados de la planta logrando de esta manera una inserción y permanencia ligada a la estabilidad y garantía de los derechos laborales.

\section{Las tensiones entre las formas de enfrentamiento de la cuestión social desde el Poder Judicial de Neuquén y la organización de los Trabajadores Sociales}

El Servicio Social se incorpora a los organismos del Poder Judicial en Argentina en el año 1930 (Oliva, 2007), en la provincia de Neuquén la inserción se va a producir en el año 1970 siendo una de las primeras profesiones convocadas desde el campo jurídico, que se inserta en el ámbito judicial. La profesión se inscribe en un ámbito caracterizado por una organización patriarcal, donde la hegemonía es el derecho. Esta profesión asume y define al resto de las y los profesio- 
nales no abogados como auxiliares de jueces y magistrados, como lo expresado en la Carta Orgánica.

El Servicio Social como profesión ha recorrido un proceso histórico donde la organización de los trabajadores está vinculada a las demandas sociales que plantea la "cuestión social" (Guerra, 2001)² producto de la expansión de la crisis capitalista y las formas de enfrentamiento que el Estado adopta desde uno de sus organismos, tiene como función, la regulación del conflicto y mantención del orden dominante. En este contexto hemos reconstruido que la profesión ha transitado tres momentos:

Período que va de 1970 hasta 1983 y recorre el proceso de dictadura militar donde puede advertirse falta de representación sindical. Si bien la actividad sindical se encontraba limitada por el contexto de dictadura, se evidencia también que desde el ámbito sindical no se asumía al sector como trabajadoras con demandas específicas (Antunes, 2001). ${ }^{3}$

La estructura judicial es altamente estratificada, jueces y magistrados se organizan en la Asociación de Magistrados que representa los intereses del sector, los denominados "empleados" del TSJ se organizan en el Sindicato de Judiciales de Neuquén (Sejun) y los denominados "profesionales auxiliares" aparecen en la historia de la institución como una franja no reconocida por ambas organizaciones, excluidos de cualquier tipo de representación que considere sus reclamos particulares.

Para Alain Bihr (1991, p. 89), estas diversas categorías de trabajadores tienen en común la precariedad del empleo y de la remuneración; desregulación de las condiciones de trabajo, en relación con las normas legales vigentes y la consabida regresión de los derechos sociales, así como la ausencia de protección y libertad sindical, configurando una tendencia a la individualización extrema de la relación.

A partir de la década de 1980 se registran Trabajadoras Sociales agremiadas al sindicato, con una representación formal individual y Trabajadoras Sociales incluidas en la Asociación de Magistrados, evidenciándose en este punto la tensión

2. "En el capitalismo monopolista el Estado pasa a intervenir directamente en la cuestión social por lo que desarrolla una modalidad de intervención tipificadas en políticas sociales que son tratadas como problemáticas particulares" (Guerra, 2001, p. 2).

3. Las dimensiones de la crisis contemporánea del sindicalismo se manifiestan a través de la fragmentación, heterogeneización y complejización de la clase que vive del trabajo, lo cual cuestiona de raíz al sindicalismo tradicional y dificulta también la organización sindical de otros segmentos que integran la clase trabajadora. 
no resuelta la tensión profesional-trabajador que va a recorrer los distintos modos de organización que van asumiendo las Trabajadoras Sociales a lo largo de la historia.

Durante este período rigen los marcos legales basados en el Paradigma de la Doctrina de la Situación Irregular, cuya Ley Nacional estaba representada por la Ley de Patronato sancionada a principios del siglo XIX. La infancia, como expresión de la "cuestión social", comienza a ser regulada a partir de la estrategia del Estado, cuyo fundamento sería la represión y reclusión de los sectores pauperizados.

La tarea profesional se dirige básicamente a determinar la "situación de riesgo" de la población usuaria, que una vez detectada desde el juzgado se deriva a los organismos ejecutores de la ley de infancia. Se trata básicamente de una estrategia ligada a la reclusión e institucionalización de ese sector poblacional. Se evidencia, la concepción de peligrosidad social (Daroqui; Guemeureman, 2000), la moralización de la pobreza, la estigmatización y como resultado la construcción social de los sectores peligrosos que requieren de una "acción efectiva del Estado". Para Daroqui y Guemureman (2000), el positivismo como pensamiento se instala en la política dando respuestas, ya no solo con la interpretación de una realidad compleja, sino brindando los instrumentos necesarios para operar sobre ella, de ahí su aporte activo a fundar los marcos teóricos, no solo del servicio social, sino de la psicología y psiquiatría.

La década de 1990 - expansión del neoliberalismo. El contexto socio económico político se caracterizó por el desmantelamiento del Estado, regresión en términos de derechos de los trabajadores, políticas de privatización y crecimiento acelerado de la pobreza que comienza a expresarse en los márgenes de las grandes ciudades. La capital de Neuquén va a iniciar un proceso de urbanización acelerado en el oeste de la ciudad donde se va a ubicar la población más pobre de la provincia.

En materia de intervención, como consecuencias de las nuevas expresiones de la "cuestión social", el nuevo milenio inaugura instrumentos legales que provocan cambios paradigmáticos en materia de infancia y violencia de género ${ }^{4}$. Se termina con un siglo de intervenciones basadas en la concepción minorizante de la infancia y de las mujeres para dar lugar a la concepción de sujetos de derechos y ciudadanía.

4. Convención Internacional del Niño/a y Adolescente, Convención Internacional sobre Eliminación de todas las formas de discriminación hacia las mujeres y Tratados sobre violencia de género. 
El cambio de los marcos legales modificaron las estructuras institucionales, los Juzgados de Menores se transforman en Juzgados de Familia, siendo cuatro en la actualidad; la Defensoría del Menor pasó a ser Defensoría de Niñez y Adolescencia. No se trató sólo del cambio de nominaciones, la institución judicial fue adquiriendo modificaciones previstas en la sanción de las correspondientes leyes que inauguraron nuevos servicios, requirieron espacios de formación, logrando en diez años ir avanzando en la adecuación institucional en todas las circunscripciones judiciales.

En este contexto y como forma de dar respuesta a la crisis, además de la modificación de la estructura el poder judicial, se convocó a profesionales especializados en violencia, nueva temática a ser abordada por la justicia. Se registra en este momento condiciones laborales compatibles con la época histórica, el poder judicial ofrece condiciones laborales en el marco de la precarización y flexibilización labo$\mathrm{ral}^{5}$ que se van a mantener casi una década.

En materia de reclamos de las condiciones laborales, los/las Trabajadores Sociales mantienen las reivindicaciones históricas referidas a la creación de la carrera judicial, el escalafón etc. Se trata de una época en la que el reclamo del sector no es asumido por ningún ámbito de representación. Durante este período comienzan a colectivizarse las demandas, sin embargo se adopta una estrategia ligada a la lógica burocrática dominante. Algunos/as compañeros/as inician juicios individuales al TSJ ubicándose como funcionarios y esperan ser reconocidos en la tarea diferencial promoviendo de esta manera promover la creación de la carrera judicial.

Período postcrisis de 2001. Se manifiesta la expresión de la crisis en la etapa de expansión del capitalismo financiero a nivel mundial. En el país toman fuerza las demandas de los movimientos sociales, de desocupados, de trabajadores organizados que van a culminar con la explosión de la crisis acontecida en el mes de diciembre de ese año.

La región no es ajena a las diversas formas de organización y movimientos, durante este período tiene vigencia dos mandatos consecutivos de Jorge Sobisch en la provincia. Se trató de un período histórico de violencia, corrupción, persecución sindical, ataques manifiestos a la ley de infancia, cuestionamiento a la independencia de poderes denunciados por distintos sectores y movimientos sociales de la provincia.

5. Ver Diario Río Negro, mayo de 1999, llamado a concurso para asistente social. 
Los/las trabajadores/as sociales y psicólogos/as comienzan a agruparse, tal como va aconteciendo en diversos espacios sociales, conformando hacia 2004 la Asociación de Profesionales Auxiliares de la Justicia.

En marzo del mencionado año se obtiene la Personería Jurídica de la Asociación, siendo los objetivos: "Ejercer la representación de los Asociados en todos aquellos aspectos que hagan a los intereses laborales como Profesionales Auxiliares Permanentes del Poder Judicial; Propiciar y promover el intercambio científico, académico, técnico y de actualización entre las distintas disciplinas que integran la asociación con el fin de tener un desarrollo y enriquecimiento de la tarea profesional dentro del poder judicial".

Se trata de la primera organización colectiva como grupo de trabajadores asalariados de la justicia, con un potencial de 40 profesionales compuestos por Trabajadores Sociales, Psicólogos y Médicas de toda la provincia.

Se inaugura una modalidad de organización social y política para llevar adelante los reclamos históricos de la carrera judicial. Se trata de una asociación que define la identidad de los/las trabajadores/as como profesionales recorriendo nuevamente el aspecto contradictorio de la tensión trabajador/profesional. Durante el período se verifican para la profesión el contexto de mayor abuso y violación de las incumbencias profesionales, dado que ante la emergencia de la crisis capitalista, la falta de respuesta de las políticas públicas a las expresiones de la "cuestión social”, se produce la personalización más extrema del trabajo.

Ante la denuncia de las condiciones laborales ${ }^{6}$, acción que el colectivo realiza de manera pública a través de medios televisivos y radiales, aparece la respuesta de la institución desde su modalidad represiva depositando en el/la trabajador/a social el incumplimiento de las Leyes de Violencia Familiar e Infancia y Adolescencia. La sanción hacia los/las trabajadores/as, se constituye en la única salida institucional para el cumplimiento de los requerimientos de los juzgados.

La sanción y el disciplinamiento a los trabajadores durante esa época se visualizó en los distintos acuerdos, mecanismos de toma de decisiones de ese poder, iniciando sumarios individuales y colectivos, sanciones y puesta en marcha de auditorías. Se inicia una persecución hacia los profesionales del sector sin precedentes en al historia del Poder Judicial de Neuquén. Un aspecto a destacar es que

6. Nota a la Secretaria de Gestión Humana con presentación del documento denominado "Colapso del Gabinete Interdisciplinario", Asociación de Profesionales de la Justicia Apajun (2006). 
la coordinación del Gabinete Interdisciplinario de Neuquén se encontraba a cargo durante ese período de un médico psiquiatra denunciado por organismos de derechos humanos ${ }^{7}$ por presunta participación en el período de terrorismo de Estado en Argentina. Se trata de un aspecto que visualizaba algunas continuidades del aparato represivo estatal.

En materia de intervención el fuero de familia habilitó el dispositivo de guardia emergente a partir de la sanción de la Ley n. 2.212 de violencia familiar para todas las demandas que ingresaban a la institución. Se trataba del uso de un teléfono celular que funciona las 24 horas, los 365 días del año, donde un abogado recepcionaba la demanda legal e inmediatamente derivaba al servicio social sin evaluación previa de la demanda, para que la trabajadora social concurriera al lugar, incluyendo los horarios nocturnos y de madrugada, para producir un informe social.

La reconstrucción de la particularidad ${ }^{8}$ de la intervención de este período visualizó que el dispositivo de guardias constituyó la respuesta que la institución brindó a la "cuestión social" en un contexto postcrisis 2001 caracterizado por la mayor expresión de desigualdad, ausencia de políticas sociales, desmantelamiento de los escasos programas de atención, siendo las trabajadoras sociales del Poder Judicial las primeras agentes de intervención ante la demanda social.

La intervención social constituía el espacio de mayor expresión del cotidiano, se inscribía en el caos, la urgencia, la inmediatez, la improvisación trasformándose en una respuesta burocrática despojada de evaluación de criterios de intervención, de proceso, de dirección. En síntesis, un escenario donde la demanda caótica de la institución implicó un escenario de violación a las incumbencias profesionales.

La reconstrucción cuantitativa de la tarea de ese período nos muestra datos tales como: más del $50 \%$ de las urgencias eran vinculadas al requerimiento de traslado de personas para entrevistas psicológicas, psiquiátricas y/o audiencias judiciales. Desde el sector se abrió una fuerte crítica a las demandas de la judica-

7. Neuquén (AN). Por tercera vez se intentará hoy iniciar el juicio contra 27 policías acusados de torturar a detenidos en la Unidad 11, la mayor cárcel de la provincia. La Asociación Zainuco, que actúa como querellante, presentó un hábeas corpus para que se les brinde protección a 15 detenidos que declararán como testigos ya que fueron víctimas de la represión, ocurrida en abril de 2004. El organismo también pidió que se excluya de la lista de testigos al psiquiatra Ignacio López Proumen atento a su presunta participación en los hechos de terrorismo de estado que fueran perpetrados durante la dictadura militar en los años 1976-1983. Diario Río Negro, 3/mayo/2010.

8. En sus estudios sobre la realidad en tanto totalidad concreta, Luckás realiza un importante análisis de las categorías de particularidad, singularidad y generalidad (Mallardi, 2012, p. 59). 
tura, en tanto, determinados requerimientos no representaban incumbencias profesionales sino acciones que conformaban parte de un ideario cultural e institucional vinculado a la representación del rol del trabajo social negativamente asumido.

La crítica situación nos interpeló como colectivo profesional y nos vimos en la tarea de generar instancias de reflexión, logrando apropiarnos de esa realidad caótica y definir incumbencias, en principio para ejercer nuestra práctica en el marco de la legislación profesional y el código de ética. Por otro lado, para no asumir las lagunas institucionales y delimitar las intervenciones profesionales que correspondían a la psicología, psiquiatría, medicina y/o abogacía.

En este período de crisis la "cuestión social” va a ser abordada desde nuevos paradigmas en la era del derecho, aparece como marco legal la Doctrina de Protección Integral de la Infancia y Adolescencia cuya principal declamación es "la infancia como sujetos de derecho". Al Trabajador Social se va a encomendar la intervención en el marco de los "derechos vulnerados" a diferencia de detectar la "situación de riesgo", estableciendo diagnósticos de vulneración de derechos universales.

Como propuesta aparece en los distintos ámbitos, académicos, judiciales, institucionales, sociales, escolares, políticos, el discurso hegemónico de la desjudicialización de la pobreza, la desinstitucionalización, desarticulando la estrategia de reclusión e institucionalización que constituyo la base metodológica del control de la población del periodo anterior. Se asume ahora como "la solución" de la "cuestión social" por parte del Estado la restitución de derechos a los niños "ciudadanos" y a las mujeres víctimas de la violencia.

En este marco se observa una creciente judicialización de derechos, ausencia de las obligaciones del Estado que deben materializarse en políticas públicas, creciente incorporación del tercer sector y creciente desarrollo de tecnicaturas que comienzan a proliferar en condiciones de extrema precariedad para abordar la cada vez mayor complejidad de la "cuestión social". El Estado provincial adopta la estrategia de descentralización, asignando la competencia a los municipios, quienes no contaron con la partida presupuestaria para hacer frente a las demandas y en un proceso acelerado debieron organizarse para abordar las situaciones delegadas.

Se ha verificado en este tiempo que la descentralización significó ausencia de la intervención del estado para asumir la "cuestión social", precarización extrema de los trabajadores y des-profesionalización del campo psicosocial, predominando técnicos y agentes denominados "operadores", figuras en quienes han delegado la 
intervención en la materia. Los nuevos paradigmas dejan en evidencia que el Estado, lejos de garantizar esos derechos proclamados en esta era, por un lado, registra la mayor ausencia de políticas públicas para abordar la "cuestión social” y por otro, pone en evidencia que la relación capital/trabajo está generando, en este período histórico, una de las mayores expresiones de deshumanización.

En materia de organización de las trabajadoras se destaca en el año 2006 un espacio de organización colectiva intradisciplinaria que surge como consecuencia de las condiciones socio ocupacionales vigentes. La intención inicial era generar un dispositivo de reflexión para problematizar la condición de género considerando las implicancias de una profesión femeneizada en un ámbito patriarcal y la condición de clase dada nuestra condición de asalariadas.

Posteriormente la propuesta se inscribió en un proyecto de extensión de la Universidad Nacional del Comahue, coordinado por la Lic. Silvia Mansilla, docente a cargo de la cátedra paralela "Seminario de Servicio Social con residencia Institucional". Este proceso constituyó un espacio fundante, pues se trató del primer ámbito intradisciplinario colectivo y organizado, donde las Trabajadoras Sociales nos reunimos durante varios meses interrumpiendo el cotidiano que desbordaba, para instituir un espacio que, sumado a los procesos que se venían gestando históricamente, va a motorizar una organización superior en la historia de los trabajadores de la justicia, la inclusión como sector específico al sindicato judicial.

El espacio de supervisión se desarrolló en el ámbito laboral, nos apropiamos del tiempo y lugar para suspender la tarea cotidiana. Si bien, reconociendo la heterogeneidad del colectivo profesional, integraron este espacio colegas con quienes habíamos desarrollado un vínculo de confianza, dado el carácter hostil y represivo de la institución. Se trata de un ámbito que fortaleció personal y políticamente al grupo, promoviendo y reorientando un proyecto profesional que se venía gestando históricamente.

Periodo 2007 a 2010 - Sindicalización de los Trabajadores Sociales. El contexto más represivo y de mayor expresión de las consecuencias de la crisis de 2001 posibilitó que se inaugurara un período trascendental, la sindicalización de los/las trabajadores sociales. Durante este período se incorpora a los reclamos históricos, carrera judicial y escalafón, la Aprobación de Incumbencias Profesionales del Servicio Social, construcción colectiva que surge a partir del período de mayor tensión y conflicto producto de la crisis y las manifestaciones creciente de la "cuestión social". 
Algunas de las estrategias que el colectivo adoptó para la acción política sindical fueron sostener la organización colectiva que el conjunto construyó en otros periodos históricos, asumir una dimensión política de la práctica, superar la dimensión profesional para asumirse como trabajadoras asalariadas con un trabajo específico en el marco de la división social y técnica del trabajo. Superar el aislamiento e integrarnos con las compañeras del interior de la provincia, dotó al reclamo un carácter más abarcativo, la asamblea es el espacio donde construimos el pliego de reclamos del sector y esbozamos la carrera judicial.

Mantuvimos la unidad y organización frente a la represión institucional en un conflicto que se mantuvo por más de ocho meses donde realizamos las siguientes medidas de fuerza: paro, quite de colaboración, asambleas en los lugares de trabajo y en distintos organismos manifestando la problemática del sector, pegatina y escarches.

Adoptamos acciones sindicales directas, esta estrategia la desplegamos en la ejecución de los concursos informando a los/las participantes que los mismos carecían de legitimidad y eran pasibles de ser impugnados por el sector, en tanto, presentaban irregularidad por la conformación del tribunal examinador, por la ausencia de veedores del colegio o sindicales. Nos asociamos con actores sociales como los colegios profesionales y la universidad, aspecto clave para deslegitimar, por ejemplo, los requerimientos que no constituían incumbencias profesionales, dando el colegio la legitimidad al reclamo. Además, constituyó una forma de ubicar el conflicto en la dimensión pública implicando un amparo social trascendente.

Realizamos denuncias públicas en medios radiales y televisivos, escarches, dado que durante el periodo postcrisis 2001 se implementaron pasantías laborales que además de constituir una profundización de la precarización laboral, los usuarios eran asistidos por estudiantes de psicología violando el derechos a la asistencia profesional además del riesgo que implica la atención preprofesional en materia de violencia de genero, maltrato infantil.

La institución baso su estrategia en acciones de represión, sanción y persecución ${ }^{9}$ a los reclamos y organización de las trabajadoras. El TSJ crea el primer

9. 2010 Testimonio Acuerdo 4517 (21 de abril 2010)

$11^{\circ}$ Equipo Interdisciplinario sobre informe de la Secretaría de Superintendencia.

Visto: Informe de medidas de quite de colaboración del Equipo Interdisciplinario informada y ratificada por la entidad gremial [...]. Que no resulta posible permitir que no ser brinde el servicio de manera adecuada, 
antecedente de sumarios colectivos a un sector, aspecto sin precedentes en la historia del Poder Judicial de Neuquén. Utiliza la estrategia de amedrentamiento individual sumariando a colegas, ${ }^{10}$ interpelando abiertamente las evaluaciones profesionales emitidas en los dictámenes. Estos sumarios constituyeron una de las mayores expresiones a la invasión a la Autonomía Profesional y nos afianzaron en la lucha por las incumbencias del Trabajo Social.

Mantuvo históricamente la negación como sujetos políticos siendo una de sus principales estrategias, basada en la definición del Artículo 11 de la Carta Orgánica, se nos prohibía cualquier tipo de medidas de fuerza: ${ }^{11}$ paros, quite de colaboración, asambleas. Estrategias que, por otro lado, fueron trascendetales para conquistar el espacio del sindicato.

Otra de las estrategias institucionales fue la fragmentación, ${ }^{12}$ separación física y distribución por distintos organismos, juzgados y defensorías de los trabajadores sociales y psicólogos enunciando taxativamente la "tabicación" como forma de ordenamiento espacial.

\footnotetext{
por que no existe fundamento jurídico válido que justifique el incumplimiento tratándose de Funcionarios que tienen competencias muy especificas asignadas por al legislación vigente y reglamentación interna, evalúe la correspondencia de la aplicación de sanciones si correspondiera. Ello sin perjuicio de continuar trabajando con las inquietudes que el grupo de profesionales tenga, en relación con el establecimiento de escalafones, protocoles de intervención o cualquier otra propuesta que deseen expresar y que podrá luego ser evaluada por el cuerpo.
}

Resuelve:

Disponer la realización de una Auditoría en el Equipo Interdisciplinario del Fuero de Familia de Neuquén Capital, a fin de determinar si existe incumplimiento de los deberes propios del cargo y propios de las funciones asignadas por la legislación y reglamentación vigente, y en caso por parte de quien, alcance $y$ detalle del mismo, con el respaldo documental correspondiente.

3) Notifiquese, cúmplase

10. S/Sumario Administrativo: Asistentes sociales.

11. XII. Secretaría de Superintendencia sobre Informe de Medidas de Fuerza Profesionales Auxiliares. Visto y Considerando: Que tal lo que surge de los informes elaborados por el jefe del Gabinete Interdisciplinario, los funcionarios que se desempeñan como psicólogos y asistentes sociales del organismo han realizado medidas de fuerzas consistentes en paros y quite de colaboración. Que teniendo en cuenta que se trata de Funcionarios de este Poder, la situación implicaría una irregularidad en el ejercicio de las funciones propias, se impone un estudio profundo de los antecedentes a fin de evaluar si corresponde que se tome alguna medida al respecto. Por lo que de conformidad Fiscal, se resuelve:

1) Pasar a estudio de los vocales los antecedentes referidos;

12. 2008 Acuerdo 4310 Cuerpo de Profesionales Auxiliares de la Justicia Sobre Reestructuración y Recategorización, se determina la desarticulación del equipo de Trajadoras Sociales y Psicólogos. 
Utilizaron la evaluación de desempeño, se calificó en forma oculta a los profesionales en sus legajos personales, medida arbitraria y discrecional con alto nivel de impunidad dado que el evaluador era un psiquiatra, dejando en evidencia la continuidad y vigencia de históricas hegemonías profesionales.

En relación a las conquistas sindicales del sector logramos constituirnos como actores políticos legítimos representados por el SINDICATO, pudiendo ser interlocutores válidos para el TSJ. Se deja atrás la argumentación histórica que opero para negar este derecho, es decir, la concepción del TSJ de que los "profesionales auxiliares" somos funcionarios. Se produjo la modificación del Estatuto del Sindicato que va a promover el ingreso de los profesionales, no sólo trabajadores sociales y psicólogos sino también abogados que no forman parte del Consejo de la Magistratura, o sea, el amplio sector subalterno de los jueces y magistrados. Si bien esta era una de las líneas políticas de la conducción de ese momento celebramos haber inaugurado, este espacio, pues representa una conquista para los trabajadores en su conjunto.

Se rompe con una de las ideas más sedimentadas en la cultura institucional ${ }^{13}$ basada en que los "profesionales" no podemos hacer huelga, paro o cualquier otro tipo de medidas de fuerza. Esta idea aparece en la historia del Poder Judicial de Neuquén tanto en magistrados y funcionarios como en compañeros administrativos y los mismos trabajadores sociales.

Se logra un espacio profesional como actor relevante en los tribunales de concursos, ahora son integrados por Trabajadores Sociales revirtiendo la práctica institucional que negaba este espacio. Se desplaza la hegemonía del derecho, médicos, psiquiatras o psicólogos para seleccionar trabajadoras sociales, incorporando veedores sindicales y de colegios de profesionales. Se suspendió el servicio de guardia para toda demanda legal y se propone un ámbito de dialogo y reflexión mediante los lineamientos profesionales, que si bien aún no se han aprobado, hemos logrado desterrar intervenciones que no constituían incumbencias socioprofesionales.

Logramos una recategorización ${ }^{14}$ ante la demanda de reconocimiento a la postergación histórica por la falta de carrera y escalafón. La misma fue discrecional

13. 2010 Testimonio Acuerdo 4517 (21 de Abril 2010).

II. Equipo Interdisciplinario sobre informe de la Secretaría de Superintendencia.

14. 2008 Acuerdo 4310 Cuerpo de Profesionales Auxiliares de la Justicia Sobre Reestructuración y Recategorización. 
pero representó un reconocimiento explícito a la postergación denunciada por los trabajadores y el primer movimiento en relación a las categorías profesionales. Esta recategorización fue producto de la propuesta asamblearia conformada por más de 300 judiciales. Representó para el sector un doble reconocimiento, de la asamblea y el reconocimiento por parte del TSJ, dado que finalmente responde al reclamo asumiendo que somos sujetos con representatividad.

Conquistas sindicales: implicancias en la práctica socio profesional. Ampliamos el grado de autonomía profesional, el fuerte cuestionamiento a las demandas de otros efectores que definían prácticas en relación a la profesión va posibilitando que las trabajadoras sociales pongan límites y definan las incumbencias profesionales. Desterramos prácticas que no constituían incumbencias profesionales, tales como traslado de personas a sede judicial para audiencia o entrevistas médicas y psicológicas, intervención en crisis psiquiátricas, adicciones, notificaciones de audiencias.

Se problematiza la idea de intervenciones coactivas del Trabajo Social, destacamos la relevancia de tensionar las acciones coativas en el contexto judicial, dado que es asumida como parte de la identidad de la institución. Ha constituido un debate que puso en relieve discusiones hacia el interior del colectivo profesional acerca de las implicancias éticas de este tipo de intervenciones.

Logramos un encuadre de intervención básico para la supervisión de régimen visitas y restitución de niños con sus padres, destacando la importancia de que estas intervenciones se desarrollen en un contexto institucional que contribuya al proceso de revinculación socio familiar. Mantuvimos alto clima de cohesión y construcción colectiva, para definir los lineamientos profesionales, construir pautas de intervención en los distintos marcos legales, instituir un espacio semanal de encuentro intradisciplinar.

Pusimos en crisis la concepción de auxiliaridad histórica del Trabajo Social ${ }^{15}$ respecto del Derecho como profesión hegemónica, abriendo el debate de las implicancias de una profesión feminizada en un contexto patriarcal. Hay un proceso de crítica y revisión de los valores dominantes históricos en relación al género en el binomio mujer-asistente social.

Entendemos que los logros alcanzados no son inamovibles, el proceso histórico da cuenta de cómo las demandas hacia el Trabajo Social se encuentran profun-

15. "El médico y posteriormente el abogado, poseedores del saber y del poder, encontraron en la asistente social, su auxiliar eficaz de cumplir con el mayor tino y delicadeza sus indicaciones" (Grassi, 1989, p. 98). 
damente ligadas al movimiento social y las respuestas que deban dar las instituciones. Hay una tendencia que la institución mantiene respecto de las respuestas a las demandas de las trabajadoras, éstas son parciales, fragmentadas, no atienden el reclamo general, no hemos logrado aún la aprobación de la carrera judicial y el escalafón pero vamos conquistando espacios trascendentales para la profesión en el ámbito del Poder Judicial de Neuquén.

\section{Conclusiones}

La lucha de las trabajadoras sociales y psicólogos/as se desenvuelve en un contexto contradictorio, donde la identidad de los mismos se manifiesta de manera central e histórica evidenciando las determinaciones de naturaleza material, objetiva y de naturaleza subjetiva que poseen las profesiones. Hay una tendencia a la proletarización que ubica a los trabajadores obligadamente a darse una respuesta para sí.

El Estado como instrumento extra económico, garantiza del orden burgués, administra la cuestión social ampliando y modificando las estructuras, exacerbando los mecanismos represivos y disciplinadores hacia a los trabajadores y de esta manera controlar el nivel de amenaza y tensión que expresa la cuestión social.

La historia de lucha de las Trabajadoras Sociales y el tratamiento de la "cuestión social" por parte del Estado nos remite a la naturaleza misma de la profesión, emergente de la división social y técnica del trabajo resultando el Estado el mercado donde vendemos la fuerza de trabajo, por lo tanto, un escenario plagado de intereses contradictorio donde el Trabajador Social debe construir un proyecto que contemple soluciones colectivas.

El devenir de este proceso histórico puso en crisis las posiciones de las trabajadoras sociales, en tanto, nos ha colocado a nosotras mismas confrontadas con la tarea cotidiana, nos ha exigido posiciones que han tenido expresiones diversas tal como lo constituye un colectivo profesional.

En la actualidad continuamos con las demandas históricas y las que se van gestando, el cambio de conducción sindical impacto en la percepción y acción política respecto del sector, se trata de un perfil ligado al mutualismo, a la burocracia sindical resultando un frente de lucha colocar nuestras demandas, no obstante logran alianza para los procesos de capacitación que proponen desde el espacio 
intradisciplinar. Mantenemos la organización colectiva y el espacio asamblearia como principal estrategia para nuestros reclamos.

Recebido em 20/2/2013 - Aprovado em 10/6/2013

\section{Referências bibliográficas}

ANDREA, Oliva. Trabajo Social y lucha de clases. Buenos Aires: Imago Mundi, 2007. ; MALLARDI, Manuel. Aportes tácticos operativos de intervención del Trabajo Social. Buenos Aires: Editorial Reuní/Universidad Nacional del Centro de la Provincia de Buenos Aires, 20/8/2012.

ANTUNES, Ricardo. ¿Adiós al Trabajo? Ensayo sobre la metamorfosis y la centralidad del mundo del trabajo. Biblioteca Latinoamericana de Servicio Social. São Paulo: Cortez, 2003. (cap. I a IV).

DARAQUI, Alcira; GUEMEUREMAN, Silvia. Los menores de hoy, de ayer y de siempre. Un recorrido histórico desde una perspectiva crítica. Buenos Aires: Revista de Ciencias Sociales, UBA, 2000.

GRASSI, Estela. La mujer y la profesión de Asistente Social: el control de la vida cotidiana. Buenos Aires: Humanitas, 1989.

GUERRA, Yolanda. "La crisis contemporánea y los impactos en la instrumentalizad del Servicio Social". Revista Polêmica: com os olhos no futuro do Servico Social. CRESS-1 Reg. 2001.

HARVEY, David. "El nuevo Imperialismo: acumulación por desposesión”. Disponible en: $<$ http://bibliotecavirtual.clacso.org.ar/ar/libros/social/2004pt/05_harvey.pdfs

IAMAMOTO, Marilda. Servicio Social y División del Trabajo. São Paulo: Cortez, 2001. . El servicio social en la contemporaneidad. Trabajo y formación profesional. São Paulo: Cortez, 2003.

NETTO, José Paulo. Capitalismo Monopolista y Servicio Social. São Paulo: Cortez, 1997. . Trabajo Social: Crítica a la Vida Cotidiana y Método de Marx. Buenos Aires: Instituto de Capacitación y Estudios Profesionales/Colegio de la Provincia de Buenos Aires, 2012. 